\title{
Development of a Simple and Fast Procedure Based on Acid Dilution for Determination of Macro and Microelements in Guarana-Based Beverages by ICP OES
}

\author{
Vinnícius Henrique C. da Silva, ${ }^{\circledR a}$ André Luiz S. da Silva Jr., ${ }^{\oplus a}$ Herick M. Santos, ${ }^{\circledR b}$ \\ Ivon P. Lôbo, ${ }^{a}$ Marcos A. Bezerra ${ }^{\circledR c}$ and Raildo M. de Jesus ${ }^{\oplus *, a}$ \\ ${ }^{a}$ Grupo de Pesquisas em Química Analítica do Sul da Bahia, \\ Departamento de Ciências Exatas e Tecnológicas, Universidade Estadual de Santa Cruz, \\ Rod. Ilhéus-Itabuna, km 16, 45662-900 Ilhéus-BA, Brazil \\ ${ }^{b}$ Grupo de Análise Instrumental Aplicada, Departamento de Química, \\ Universidade Federal de São Carlos, Rod. Washington Luiz, km 235, \\ 13565-905 São Carlos-SP, Brazil \\ ${ }^{c}$ Departamento de Ciências e Tecnologias, Universidade Estadual do Sudoeste da Bahia, \\ Campus de Jequié, Rua José Moreira Sobrinho s/n, 45208-091 Jequié-BA, Brazil
}

\begin{abstract}
A simple analytical procedure is proposed for the direct analysis of guarana-based beverages in order to determine nutrient elements by inductively coupled plasma optical emission spectrometry (ICP OES). A Box-Behnken design, combined with Derringer's desirability function, was applied to the simultaneous optimization of the ICP OES radiofrequency (RF), sample volume and nitric acid concentration. Using this approach, optimal conditions were established as RF power of $1.40 \mathrm{~kW}$, and $5.0 \mathrm{~mL}$ of sample diluted twice with $0.5 \mathrm{~mol} \mathrm{~L}^{-1} \mathrm{HNO}_{3}$. The optimized procedure allowed the determination of $\mathrm{Cu}, \mathrm{Fe}, \mathrm{Mn}, \mathrm{Zn}, \mathrm{K}, \mathrm{Ca}, \mathrm{S}, \mathrm{P}$ and $\mathrm{Mg}$ with limits of quantification of $10.0,2.0,0.6,6.0,66.0,65.0,235,40.0$ and $20.0 \mu \mathrm{g} \mathrm{L}-1$, respectively. Accuracy of the method was evaluated through analysis of water standard reference material (SRM NIST 1643f) and by additionrecovery experiments, in which satisfactory recoveries were obtained. The procedure was applied for the analysis of guarana-based soft and energy drinks. The concentration ranges $\left(\mathrm{mg} \mathrm{L}^{-1}\right)$ were: 0.36-43.3 (Ca), 4.04-192 (K), 0.36-44.8 (Mg), 10.1-1,073 (S), 0.04-92.4 (P), < 0.010-0.0174 (Cu), $<0.002-0.294(\mathrm{Fe}),<0.006-0.06(\mathrm{Zn})$ and $<0.0006-0.168(\mathrm{Mn})$.
\end{abstract}

Keywords: Paullinia cupana, guarana, Box-Behnken design, sample preparation, soft and energy drinks, ICP OES, elemental composition

\section{Introduction}

Guarana (Paullinia cupana Kunth) is a plant originally from the Amazon and its fruit is widely consumed worldwide since guarana extract is one of the raw materials used for the production of soft and energy drinks. ${ }^{1}$ According to the Brazilian Institute of Geography and Statistics (IBGE), Brazil is the world's leading producer and consumer of guarana. The State of Bahia is the largest national producer, accounting for $60 \%$ of the annual production of 2,644 tons..$^{2}$ It is estimated that approximately $70 \%$ of all guarana seed production is purchased by the beverage industry, in which guarana soft drinks are some of the most consumed. ${ }^{3,4}$

*e-mail: rmota@uesc.br
Guarana-based beverages are consumed by people of all age groups. Per capita consumption in Brazil is $0.47 \mathrm{~L}$ per person per year for energy drinks and $61.82 \mathrm{~L}$ per person per year for soft drinks. ${ }^{5}$ It is known that soft and energy drinks are sources of macro and microelements essential to the human organism. ${ }^{6-8}$ However, the intake of large amounts of these elements may cause health risks, especially in children, whose deleterious effects may be more critical. ${ }^{9}$ Therefore, the concentration of such elements in guarana-based beverages must be monitored to ensure food safety according to recommendations of regulatory agencies.

The analytical methods usually applied for elemental determination in beverage samples are based on spectroanalytical techniques such as inductively coupled plasma optical emission spectrometry (ICP OES), ${ }^{10,11}$ energy 
dispersive X-ray fluorescence (ED-XRF), ${ }^{12,13}$ inductively coupled plasma mass spectrometry (ICP-MS), ${ }^{14,15}$ and flame atomic absorption spectrometry (F AAS). ${ }^{16,17}$ Elemental determination via these instruments commonly involves a sample pre-treatment step before analysis. For this purpose, the samples are frequently acid-digested in a digester block or in a closed system employing Teflon bombs or microwave irradiation. ${ }^{18}$

Microwave-assisted digestion is considered state of the art for sample preparation procedures, offering advantages such as high digestion efficiency, minimization of external contamination and reduction of volatile analyte losses. The use of microwave irradiation has been recently reported for acid digestion of beverage samples such as isotonic and energy drinks ${ }^{6}$ and fruit juices ${ }^{14,19}$ for multi-element determination by ICP-based techniques. However, the cost of purchase and maintenance of microwave furnaces as well as the limited number of digested samples per run are some drawbacks of the microwave system..$^{20}$ In this sense, direct analysis using simple dilution and acidification of samples is a feasible strategy for some liquid samples.

The optimization of procedures for beverage analysis has been performed by applying multivariate strategies. ${ }^{21}$ In recent work, ${ }^{22}$ a Box-Benhken design was used to establish the optimal conditions for the determination of $\mathrm{Ca}, \mathrm{Fe}, \mathrm{K}, \mathrm{Mg}$ and $\mathrm{Na}$ in industrialized apple juices. Samples were diluted (1:1) and acidified with $0.8 \mathrm{~mol} \mathrm{~L}^{-1} \mathrm{HNO}_{3}$, before analysis by high-resolution continuum source flame atomic absorption spectrometry (HR-CS-F AAS). The proposed method was compared with acid digestion and acceptable agreement was obtained for the results.

Multivariate optimization has been successfully used in the development of analytical procedures for the analysis of several food and beverage samples. ${ }^{23}$ Jalbani et al. ${ }^{24}$ used a $2^{3}$ factorial and central composite design for the optimization of a method based on ultrasound-assisted pseudo-digestion, for $\mathrm{Al}$ determination in soft drinks by electrothermal atomic absorption spectrometry (ET AAS). Castro and Baccan ${ }^{25}$ applied a $2^{4-1}$ fractional factorial design in the optimization of a pre-concentration procedure for subsequent $\mathrm{Cu}$ determination in soft drinks by F AAS. Froes et al. ${ }^{26}$ optimized the ICP OES instrument conditions (radiofrequency power, nebulization gas flow and sample flow rate) for determination of $\mathrm{Al}, \mathrm{Ba}, \mathrm{Ca}, \mathrm{Cd}, \mathrm{Cr}, \mathrm{Cu}, \mathrm{K}$, $\mathrm{Mg}, \mathrm{Na}, \mathrm{Ni}, \mathrm{Pb}, \mathrm{Sn}$ and $\mathrm{Zn}$ in soft drink samples by applying a $2^{3}$ factorial and central composite design. Milani et al. ${ }^{27}$ also optimized the instrument conditions of the ICP OES for the determination of 16 trace elements (Al, As, Cd, Co, $\mathrm{Cr}, \mathrm{Cu}, \mathrm{Fe}, \mathrm{Li}, \mathrm{Mn}, \mathrm{Ni}, \mathrm{Pb}, \mathrm{Sb}, \mathrm{Se}, \mathrm{Sr}, \mathrm{Sn}$, and $\mathrm{Zn}$ ) in tea drinks, soy-based beverages, and whole fruit juices.
Unlike the univariate methods, multivariate optimization approaches by using surface response methodologies need a lower number of experiments. In addition, it is possible to evaluate synergistic or antagonistic effects among the studied factors such as instrumental parameters and sample preparation conditions. ${ }^{28}$ Thus, this work aimed to develop an analytical procedure based on dilution and direct analysis of guarana-based beverages for the simultaneous determination of $\mathrm{K}, \mathrm{Ca}, \mathrm{Mg}, \mathrm{S}, \mathrm{P}, \mathrm{Fe}, \mathrm{Cu}, \mathrm{Mn}$, and $\mathrm{Zn}$ by ICP OES. In this way, it is expected to contribute to data acquisition about the nutritional value and to ensure the food safety of these beverages.

\section{Experimental}

Instrumentation

The measurements were performed using a 10-ES axially viewed ICP OES (Varian, Mulgrave, Australia). A Meinhard concentric nebulizer and a single pass cyclonic spray chamber were used as a sample introduction system. Argon 99.998\% (White Martins-Praxair, Bahia, Brazil) was used for plasma generation and in a nebulization system. The ICP OES instrument conditions were adjusted to a radio-frequency power of $1.40 \mathrm{~kW}$, nebulization pressure of $150 \mathrm{kPa}$, plasma and auxiliary gas flow rate of 15.0 and $1.50 \mathrm{~L} \mathrm{~min}^{-1}$, respectively. The following emission lines (with the indication of I for atomic lines and II for ionic lines) were selected for the analytes: $\mathrm{Cu}$ (I) 327.395; Fe (II) 238.204; Mn (II) 257.610; Zn (I) 213.857; Ca (II) 373.690; K (I) 766.491; P (I) 213.618; S (I) 181.972; $\mathrm{Mg}$ (II) 279.800; Mg (II) 280.270; Mg (I) 285.213. An Elmasonic $^{\circledR}$ ultrasonic bath (Elma, Singen, Germany) operating at $350 \mathrm{~W}$ power was used to degas the samples. For the measurement of dissolved solid contents, a RM 732 refractometer (Lorben, São Paulo, Brazil) with Brix scale $0-32^{\circ}$ was used.

Reagents, solutions, and samples

All working solutions were prepared using ultrapure water with resistivity $18.2 \mathrm{M} \Omega \mathrm{cm}$ obtained from a Milli-Q ${ }^{\circledast}$ system (Milipore, Bedford, USA) and analytical grade reagents. Nitric acid $65 \%\left(\mathrm{~m} \mathrm{~m}^{-1}\right)$ EMSURE $^{\circledR}$ (Merck, Darmstadt, Germany), hydrogen peroxide 30\% $\left(\mathrm{m} \mathrm{m}^{-1}\right)$ EMSURE $^{\circledR}$ (Merck, Darmstadt, Germany) and hydrochloric acid 37\% $\left(\mathrm{m} \mathrm{m}^{-1}\right)$ EMSURE $^{\circledR}$ (Merck, Darmstadt, Germany) were used for sample digestion. Standard solutions used for analytical calibration curves and addition-recovery experiments were prepared by appropriate dilutions of mono-element stock solutions of 
1,000 or 10,000 mg L-1 (Specsol, São Paulo, Brazil). All glassware was decontaminated in $10 \%\left(\mathrm{v} \mathrm{v}^{-1}\right)$ nitric acid for $24 \mathrm{~h}$ and rinsed with ultrapure water.

A total of twenty-eight samples of guarana-based soft $(n=14)$ and energy drinks $(n=14)$ of different brands in metal or plastic packaging were purchased in supermarkets from Itabuna and Ilhéus cities (Bahia, Brazil). The samples were stored in a freezer at $5^{\circ} \mathrm{C}$ until analysis.

\section{Optimization strategy for the direct analysis procedure}

The analytical procedure based on the direct analysis of beverages for determination of $\mathrm{Ca}, \mathrm{K}, \mathrm{Mg}, \mathrm{P}, \mathrm{S}, \mathrm{Cu}$, $\mathrm{Fe}, \mathrm{Mn}$, and $\mathrm{Zn}$ by ICP OES was optimized applying a Box-Behnken design and response surface methodology. Sample volume (5.0, 6.5 and $8.0 \mathrm{~mL}$ ) was used as one of the investigated variables. For this, the samples were 2.0-, 1.54- and 1.25-fold diluted, respectively, after adjusting the sample volume to $10.0-\mathrm{mL}$ volumetric flasks. The other two variables were the nitric acid concentration in the final solution $\left(0.50,1.25\right.$ and $\left.2.00 \mathrm{~mol} \mathrm{~L}^{-1}\right)$ and the RF power applied in the ICP OES (1.20, 1.30 and $1.40 \mathrm{~kW})$. The BoxBehnken design consisted of a set of 15 experiments (run at random order) including 3 central points for evaluation of the experimental error, which can be seen in Table 1.

The emission intensities obtained for the analytes were established as analytical responses in each experimental point (Table S1, in the Supplementary Information (SI) section). A chemometric approach based on Derringer's desirability function ${ }^{29}$ was explored for simultaneous optimization, in which the evaluation criterion was to maximize the analytical response for each analyte. Equation 1 was applied to combine all responses in overall desirability (OD) from individual desirability values $\left(d_{n}\right)$. The statistical data analysis was performed by using Statistica version $12.0^{30}$ (Statsoft, USA) and Design Expert version $6.0 .4^{31}$ (Minneapolis, MN, USA) software.

$$
\mathrm{OD}=\sqrt[n]{\mathrm{d}_{1} \mathrm{~d}_{2} \mathrm{~d}_{3} \ldots \mathrm{d}_{\mathrm{n}}}
$$

\section{Direct analysis of guarana-based beverage samples}

A sample volume of $5.0 \mathrm{~mL}$ was previously degasified for $15 \mathrm{~min}$ in an ultrasonic bath operating at $100 \%$ power and $80 \mathrm{~Hz}$ frequency. Then, an aliquot of $357 \mu \mathrm{L}$ of $\mathrm{HNO}_{3}\left(65 \% \mathrm{~m} \mathrm{~m}^{-1}\right)$ was added as well as ultrapure water until reaching a volume of $10.0 \mathrm{~mL}$, resulting in a final concentration of $0.5 \mathrm{~mol} \mathrm{~L} \mathrm{HNO}_{3}$. After the procedure, the sample solutions were analyzed by ICP OES for multi-element determination using an external calibration technique. The same analytical procedure was also applied for the analysis of standard reference material of water (SRM NIST 1643f). All samples were prepared and analyzed in triplicate.

\section{Microwave-assisted digestion}

As a comparative method, a microwave-assisted digestion was performed. For this purpose, a sample volume of $10.0 \mathrm{~mL}$ previously degasified in an ultrasonic bath was transferred to the perfluoroalkoxy (PFA) vessels, and a digesting solution, consisting of $2.60 \mathrm{~mL}$ of $\mathrm{HNO}_{3}$ $\left(65 \% \mathrm{v} \mathrm{v}^{-1}\right), 0.60 \mathrm{~mL}$ of $\mathrm{HCl}\left(37 \% \mathrm{v} \mathrm{v}^{-1}\right)$ and $1.80 \mathrm{~mL}$ of $\mathrm{H}_{2} \mathrm{O}_{2}$, were added. Subsequently, the samples were acid digested in a microwave system applying a heating program of 4 stages (time (in min)/power (in W)/ temperature (in ${ }^{\circ} \mathrm{C}$ )): (i) 2/1,600/120, (ii) 8/1,600/120; (iii) 5/1,600/180, (iv) 15/1,600/180, and followed by cool-down for $15 \mathrm{~min}$. The final digests were diluted up to $20 \mathrm{~mL}$ with ultrapure water and analyzed by ICP OES. All samples were prepared and analyzed in triplicate.

\section{Verification of the proposed procedure}

The proposed procedure was verified according to the following analytical parameters: limits of detection (LOD), limits of quantification (LOQ), matrix effects, plasma robustness, precision, and accuracy. Matrix effects were evaluated through statistical comparison between the slopes of calibration curves $(n=3)$ built by using external calibration (EC) in $2 \%\left(\mathrm{v} \mathrm{v}^{-1}\right) \mathrm{HNO}_{3}$ medium and standard addition method (SA). In addition, the determination coefficients were also analyzed. ${ }^{32}$

\section{Limits of detection and quantification}

LOD and LOQ values were calculated using the relative standard deviation from ten consecutive measurements of the analytical blank $\left(\operatorname{RSD}_{\mathrm{bl}}\right)$ and the background equivalent concentration (BEC), as follows: $\mathrm{LOD}=\left(\mathrm{RSD}_{\mathrm{b} 1} \times \mathrm{BEC} \times 3\right) / 100$; and $\mathrm{LOQ}=\left(\mathrm{RSD}_{\mathrm{bl}} \times \mathrm{BEC} \times 10\right) / 100$. The background equivalent concentration was obtained by $\mathrm{BEC}=\mathrm{C}_{\text {analyte }} / \mathrm{SBR}$, where $\mathrm{C}_{\text {analyte }}$ is the analyte concentration in the standard solution and SBR is the signal-to-background ratio. The latter is derived from the equation $\mathrm{SBR}=\left(\mathrm{I}_{\text {analyte }}-\mathrm{I}_{\text {blank }}\right) / \mathrm{I}_{\text {blank }}$ ( $\mathrm{I}_{\text {analyte }}$ and $\mathrm{I}_{\text {blank }}$ for analyte and blank signals, respectively). ${ }^{33}$

\section{Precision, accuracy, and plasma robustness}

The precision of the proposed method was verified by the relative standard deviation obtained from seven 
measurements of the same beverage sample. For evaluation of the method's accuracy, the analyses of a standard reference material of water (SRM NIST 1643f) and addition-recovery experiments were performed. Plasma robustness was evaluated by the ratio between emission intensities generated for magnesium ionic (280.270) and atomic (285.213) lines, $\mathrm{Mg} \mathrm{II/Mg} \mathrm{I,} \mathrm{and} \mathrm{subsequent}$ multiplication by the correction factor $1.8 .^{34}$

\section{Results and Discussion}

\section{Optimization of experimental conditions for direct analysis of beverages}

The optimum values for the studied variables (sample volume, $\mathrm{HNO}_{3}$ concentration, and radiofrequency (RF) power) were obtained by using a Box-Behnken design, in which the emission intensity for each analyte was employed as an analytical response. To establish a compromise condition, the overall desirability function was applied for simultaneous optimization. The experimental matrix and obtained results are shown in Table 1.

A quadratic model was suitable to describe the experimental data. According to results of the analysis of variance (ANOVA) shown in Table 2, the ratio between mean square of regression (MSR) and mean square of residue (MSRes) was approximately 3 times higher than the tabulated Fisher's $F$-test value at the $95 \%$ confidence level $\left(F_{\text {calculated }}, 14.49>F_{\text {tabulated }}, 4.77\right)$, indicating that the regression of the quadratic model is highly significant. In addition, the mathematical model did not show lack-of-fit taking into account that the ratio between mean square of lack-of-fit (MSlof) and mean square of pure error (MSpe) $\left(F_{\text {calculated }}=0.83\right)$ was less than $F_{\text {tabulated }}(19.16)$.

The quality of the obtained model was also evaluated by analyzing the plot of predicted versus observed values and the residual plot (Figure 1). An excellent correlation ( $>0.900)$ between the experimental and predicted values

Table 1. Experimental matrix from a Box-Behnken design for multivariate optimization of the procedure for direct analysis of guarana-based beverages

\begin{tabular}{|c|c|c|c|c|c|}
\hline \multirow{2}{*}{$\begin{array}{l}\text { Random execution } \\
\text { order }\end{array}$} & \multirow{2}{*}{$\begin{array}{l}\text { Standard } \\
\text { order }\end{array}$} & \multicolumn{3}{|c|}{ Factors } & \multirow{2}{*}{$\begin{array}{c}\text { Overall } \\
\text { desirability }\end{array}$} \\
\hline & & $\begin{array}{c}\mathrm{HNO}_{3} \text { concentration / } \\
\left(\mathrm{mol} \mathrm{L}^{-1}\right)\end{array}$ & Volume / mL & $\mathrm{RF}$ power / $\mathrm{kW}$ & \\
\hline 6 & 1 & $0.50(-1)$ & $5.00(-1)$ & $1.3(0)$ & 0.896 \\
\hline $14^{\mathrm{a}}$ & 2 & $2.00(1)$ & $5.00(-1)$ & $1.3(0)$ & 0.803 \\
\hline 9 & 3 & $0.50(-1)$ & $8.00(1)$ & $1.3(0)$ & 0.752 \\
\hline 10 & 4 & $2.00(1)$ & $8.00(1)$ & $1.3(0)$ & 0.734 \\
\hline 7 & 5 & $0.50(-1)$ & $6.50(0)$ & $1.2(-1)$ & 0.721 \\
\hline 2 & 6 & $2.00(1)$ & $6.50(0)$ & $1.2(-1)$ & 0.686 \\
\hline 11 & 7 & $0.50(-1)$ & $6.50(0)$ & $1.4(1)$ & 0.950 \\
\hline 5 & 8 & $2.00(1)$ & $6.50(0)$ & $1.4(1)$ & 0.815 \\
\hline 8 & 9 & $1.25(0)$ & $5.00(-1)$ & $1.2(-1)$ & 0.768 \\
\hline 3 & 10 & $1.25(0)$ & $8.00(1)$ & $1.2(-1)$ & 0.670 \\
\hline 4 & 11 & $1.25(0)$ & $5.00(-1)$ & $1.4(1)$ & 0.905 \\
\hline $15^{\mathrm{a}}$ & 12 & $1.25(0)$ & $8.00(1)$ & $1.4(1)$ & 0.786 \\
\hline 1 & 13 & $1.25(0)$ & $6.5(0)$ & $1.3(0)$ & 0.783 \\
\hline 12 & 14 & $1.25(0)$ & $6.5(0)$ & $1.3(0)$ & 0.774 \\
\hline $13^{\mathrm{a}}$ & 15 & $1.25(0)$ & $6.5(0)$ & $1.3(0)$ & 0.732 \\
\hline
\end{tabular}

${ }^{a}$ Central point. RF: ICP OES radiofrequency; ICP OES: inductively coupled plasma optical emission spectrometry; the coded values are indicated in parentheses.

Table 2. Analysis of variance of the quadratic model fitted to overall desirability from Box-Behnken design

\begin{tabular}{|c|c|c|c|c|c|c|}
\hline Source of variation & SS & df & MS & $F_{\text {calculated }}$ value & $F_{\text {tabulated }}$ value & $\mathrm{R}^{2}$ \\
\hline Regression & 0.086 & 9 & $9.53 \times 10^{-3}$ & 14.49 & 4.77 & 0.963 \\
\hline Residual & $3.29 \times 10^{-3}$ & 5 & $6.57 \times 10^{-4}$ & & & \\
\hline Lack-of-fit & $1.83 \times 10^{-3}$ & 3 & $6.09 \times 10^{-4}$ & 0.83 & 19.16 & \\
\hline Pure error & $1.46 \times 10^{-3}$ & 2 & $7.29 \times 10^{-4}$ & & & \\
\hline Total & 0.089 & 14 & & & & \\
\hline
\end{tabular}

SS: sum of squares; df: degree of freedom; MS: mean squares; ${ }^{2}:$ determination coefficient; Fisher's $F$-test: $F_{\text {calculated }}$ and $F_{\text {tabulated }}$ values. 
was found. Moreover, a random residual distribution was observed in the residues plot, confirming the good quality of the fitted model.

Equation 2 presents the quadratic model calculated as a function of the overall desirability. The significant coefficients are shown in bold. The sample volume and RF power were statistically significant at the $95 \%$ confidence level, however only the second variable had a positive effect on analytical response. The increase of RF power in ICP OES (at a low nebulization flow rate) favors the formation of a more energetic plasma (robust conditions), resulting in a higher energy transfer to the samples. Although this condition leads to more background interference, the increase of the analytical signal can be compensated. ${ }^{28,35}$ On the other hand, dilution of sample volume leads to a greater $\mathrm{Mg} \mathrm{II} / \mathrm{Mg}$ I ratio, ensuring values higher than 8 and providing, therefore, greater plasma robustness. ${ }^{26}$

$\mathrm{OD}=(0.7910 \pm 0.007)-(0.0351 \pm 0.009)\left[\mathrm{HNO}_{3}\right]-$

$(\mathbf{0 . 0 5 3 6} \pm \mathbf{0 . 0 0 9})[\mathrm{vol}]+(\mathbf{0 . 0 7 6 1} \pm \mathbf{0 . 0 0 9})[\mathrm{RF}]+$

$(0.0187 \pm 0.0135)\left[\mathrm{HNO}_{3}\right][\mathrm{vol}]-(0.0248 \pm 0.0135)\left[\mathrm{HNO}_{3}\right][\mathrm{RF}]$

$-(0.0052 \pm 0.0135)[\mathrm{vol}][\mathrm{RF}]-(0.0110 \pm 0.0070)\left[\mathrm{HNO}_{3}\right]^{2}$

$-(0.0536 \pm 0.0095)[\mathrm{vol}]^{2}-(0.0761 \pm 0.0095)[\mathrm{RF}]^{2}$

(significant coefficients in bold)

To determine the optimal conditions, the overall desirability function was applied using Statistica 12.0 software. ${ }^{30}$ Figure 2 shows the response surface generated from the quadratic model to describe the OD behavior by ranging the levels, factors, and interactions. As can be observed, the optimum analytical response (higher OD) was obtained when sample volume and nitric acid concentration were kept at the lower levels and by increasing the RF power to the upper level in the Box-Behnken design. The best theoretical conditions suggested by the software were $\mathrm{RF}$ power at $1.40 \mathrm{~kW}$, a sample volume of $5.0 \mathrm{~mL}$, and $0.5 \mathrm{~mol} \mathrm{~L}^{-1} \mathrm{HNO}_{3}$. Although the response surface indicates a trend for higher values of RF power and lower values for the sample volume, we chose not to extrapolate these

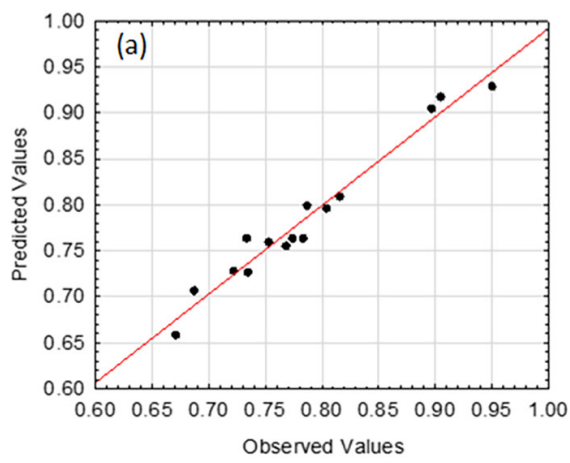

values since the increase in RF power may decrease the useful life of ICP OES components. In addition, smaller sample volumes can generate results below the limit of quantification for some elements.

For assessment of the model's predictability, an analysis was performed in triplicate by using the suggested experimental conditions. The results show that there was no significant difference between the OD value obtained experimentally $(0.95 \pm 0.05)$ and the theoretical OD value (0.94), proving the good prediction capacity of the proposed model. Therefore, we chose to work under the optimized conditions for direct analysis of guarana-based beverage samples by ICP OES. Considering that all analyzed beverages had a degree Brix value less than $10 \%\left(\mathrm{~m} \mathrm{v}^{-1}\right)$, the total dissolved solids (TDS) do not influence the nebulization of the sample, considering, in this case, the dilution of the sample and the adequate capacity of concentric functioning (Meinhard) nebulizers at 5\% $\left(\mathrm{m} \mathrm{v}^{-1}\right)$ for TDS. ${ }^{11}$ These results were very consistent with other studies that employed direct analysis for determination of metals in beverage samples by spectrometric techniques. ${ }^{22,26,36}$ In these studies, only a simple dilution and acidification of the samples to obtain a $2 \%\left(\mathrm{v} \mathrm{v}^{-1}\right) \mathrm{HNO}_{3}$ solution were performed.

Comparison between microwave-assisted digestion and the proposed procedure

A statistical paired Student's $t$-test was applied to compare the results obtained by the proposed procedure using the optimized conditions and from microwave-assisted digestion. For this purpose, ten guarana-based beverage samples were randomly selected. The results in Table 3 show that there was no statistically significant difference (95\% confidence level) between the concentrations found for the analytes after sample acid digestion in a microwave system or by using the optimized direct analysis procedure, since that the calculated $t$-values were less than the $t$-critical value $\left(t_{\text {crit }}=2.77\right)$ for all analyzed samples.

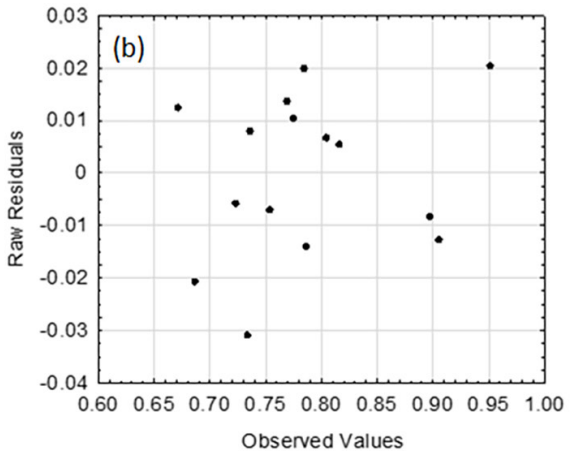

Figure 1. Plot of (a) observed vs. predicted values, and (b) predicted $v s$. residual values. 
(a)

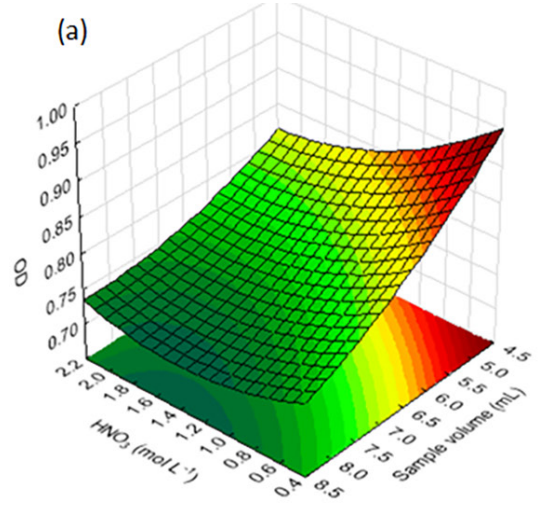

(b)

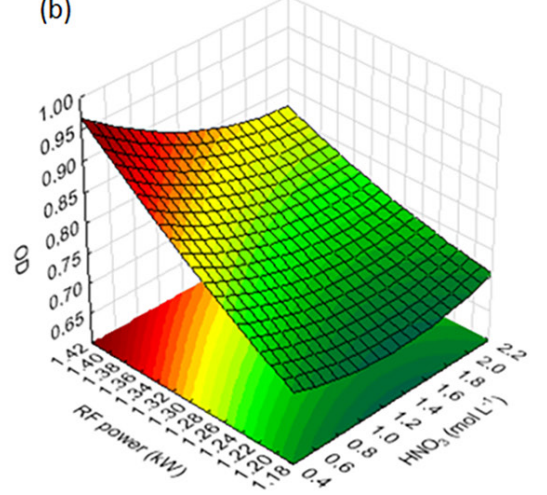

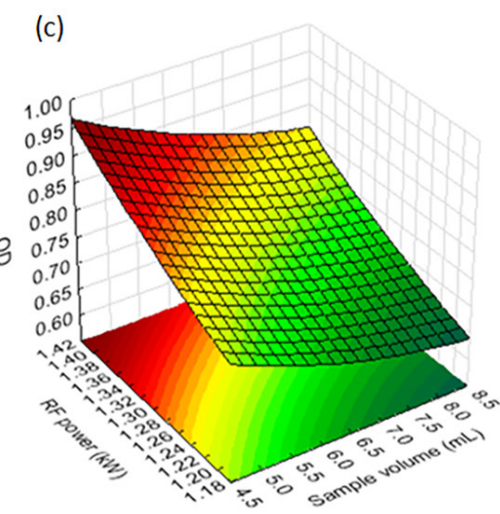

Figure 2. Response surfaces generated from Box-Behnken design for overall desirability for: (a) sample volume $\times \mathrm{HNO}_{3}$ concentration, (b) $\mathrm{RF}$ power $\times$ $\mathrm{HNO}_{3}$ concentration and (c) RF power $\times$ sample volume; OD: overall desirability.

Verification of the analytical procedure

\section{Evaluation of matrix effects}

The matrix effects were evaluated through the preparation of an aqueous calibration curve in a $2 \%\left(\mathrm{v} \mathrm{v}^{-1}\right)$ $\mathrm{HNO}_{3}$ solution (external calibration) and by using the standard addition method. For this purpose, the slopes and determination coefficients obtained in each calibration curve were compared statistically. All results are shown in Table S2 (see SI section).

After the application of the Fisher's $F$ - and paired
Student's $t$-tests, it was observed that the calculated $t$-values were less than $t$-critical (2.78) at the $95 \%$ confidence level. These results indicate a non-significant difference between the slopes of the analytical calibration curves prepared by EC or SA method, showing that there was no evidence of critical matrix effects. Additionally, satisfactory determination coefficients were observed for all analytes by using both calibration methods $\left(\mathrm{R}^{2}>\right.$ 0.9990 , determination coefficient). Therefore, the external calibration was selected for the direct analysis procedure, as it is simpler and faster.

Table 3. Concentration of macro and microelements in some guarana-based soft and energy drinks by applying the optimized direct analysis procedure (DA) and after microwave-assisted digestion (MW)

\begin{tabular}{|c|c|c|c|c|c|c|c|c|c|c|}
\hline Drink code & Procedure & $\begin{array}{c}\mathrm{Cu} / \\
\left(\mu \mathrm{g} \mathrm{L}^{-1}\right)\end{array}$ & $\begin{array}{c}\mathrm{Fe} / \\
\left(\mu \mathrm{g} \mathrm{L}^{-1}\right)\end{array}$ & $\begin{array}{c}\mathrm{Zn} / \\
\left(\mu \mathrm{g} \mathrm{L}^{-1}\right)\end{array}$ & $\begin{array}{c}\mathrm{Mn} / \\
\left(\mu \mathrm{g} \mathrm{L}^{-1}\right) \\
\end{array}$ & $\begin{array}{c}\mathrm{Ca} / \\
\left(\mathrm{mg} \mathrm{L}^{-1}\right)\end{array}$ & $\begin{array}{c}\mathrm{K} / \\
\left(\mathrm{mg} \mathrm{L}^{-1}\right) \\
\end{array}$ & $\begin{array}{c}\mathrm{Mg} / \\
\left(\mathrm{mg} \mathrm{L}^{-1}\right)\end{array}$ & $\begin{array}{c}\mathrm{S} / \\
\left(\mathrm{mg} \mathrm{L}^{-1}\right) \\
\end{array}$ & $\begin{array}{c}\mathrm{P} / \\
\left(\mathrm{mg} \mathrm{L}^{-1}\right) \\
\end{array}$ \\
\hline \multirow{2}{*}{ GRT } & MW & $<10.0$ & $129 \pm 7$ & $11.5 \pm 1.0$ & $71.3 \pm 6.7$ & $38.3 \pm 0.4$ & $51.3 \pm 5.0$ & $24.7 \pm 1.8$ & $157 \pm 14$ & $0.45 \pm 0.05$ \\
\hline & DA & $<10.0$ & $124 \pm 6$ & $10.4 \pm 1.3$ & $66.3 \pm 1.7$ & $36.4 \pm 1.1$ & $43.9 \pm 2.4$ & $23.7 \pm 0.5$ & $166 \pm 3$ & $0.55 \pm 0.02$ \\
\hline \multirow{2}{*}{ MGT } & MW & $11.2 \pm 0.2$ & $133 \pm 4$ & $<6.0$ & $10.2 \pm 1.4$ & $17.2 \pm 1.3$ & $37.8 \pm 2.6$ & $3.97 \pm 0.54$ & $556 \pm 20$ & $0.43 \pm 0.04$ \\
\hline & DA & $10.9 \pm 1.7$ & $127 \pm 8$ & $<6.0$ & $8.7 \pm 0.46$ & $18.7 \pm 0.4$ & $32.5 \pm 0.7$ & $3.27 \pm 0.11$ & $553 \pm 4$ & $0.45 \pm 0.12$ \\
\hline \multirow{2}{*}{ FUS } & MW & $13.9 \pm 0.6$ & $27.7 \pm 3.4$ & $19.6 \pm 2.8$ & $10.2 \pm 1.5$ & $5.48 \pm 1.36$ & $154 \pm 8$ & $0.95 \pm 0.10$ & $1055 \pm 47$ & $0.64 \pm 0.03$ \\
\hline & DA & $15.3 \pm 0.8$ & $20.3 \pm 0.5$ & $18.1 \pm 4.0$ & $11.4 \pm 0.4$ & $5.57 \pm 0.50$ & $158 \pm 1$ & $1.00 \pm 0.05$ & $1073 \pm 43$ & $0.63 \pm 0.09$ \\
\hline \multirow{2}{*}{ EUP } & MW & $11.1 \pm 0.2$ & $13.4 \pm 1.7$ & $<6.0$ & $0.84 \pm 0.2$ & $1.45 \pm 0.07$ & $18.8 \pm 1.6$ & $2.30 \pm 0.31$ & $1015 \pm 17$ & $0.18 \pm 0.03$ \\
\hline & DA & $10.7 \pm 0.5$ & $10.8 \pm 1.0$ & $<6.0$ & $1.00 \pm 0.03$ & $1.56 \pm 0.18$ & $17.7 \pm 0.9$ & $2.14 \pm 0.12$ & $1006 \pm 8$ & $0.16 \pm 0.01$ \\
\hline \multirow{2}{*}{ BIV } & MW & $13.8 \pm 2.9$ & $50.4 \pm 2.8$ & $<6.0$ & $13.1 \pm 2.5$ & $17.2 \pm 1.8$ & $105 \pm 5$ & $22.6 \pm 1.2$ & $973 \pm 79$ & $0.85 \pm 0.09$ \\
\hline & DA & $11.7 \pm 2.5$ & $47.0 \pm 2.1$ & $<6.0$ & $12.2 \pm 0.7$ & $15.8 \pm 1.4$ & $110 \pm 1$ & $23.5 \pm 0.4$ & $1007 \pm 22$ & $0.73 \pm 0.04$ \\
\hline \multirow{2}{*}{ GA } & MW & $<10.0$ & $7.20 \pm 1.2$ & $<6.0$ & $7.60 \pm 1.20$ & $5.95 \pm 1.08$ & $16.1 \pm 1.2$ & $1.90 \pm 0.04$ & $15.4 \pm 1.1$ & $0.39 \pm 0.09$ \\
\hline & DA & $<10.0$ & $5.40 \pm 1.2$ & $<6.0$ & $5.98 \pm 0.54$ & $6.37 \pm 0.72$ & $15.7 \pm 0.2$ & $1.82 \pm 0.07$ & $15.2 \pm 1.3$ & $0.41 \pm 0.12$ \\
\hline \multirow{2}{*}{ KTP } & MW & $<10.0$ & $29.1 \pm 4.4$ & $<6.0$ & $2.16 \pm 0.84$ & $16.1 \pm 1.7$ & $40.8 \pm 0.8$ & $7.70 \pm 1.20$ & $49.4 \pm 9.4$ & $1.58 \pm 0.08$ \\
\hline & DA & $<10.0$ & $33.7 \pm 5.2$ & $<6.0$ & $2.45 \pm 0.51$ & $16.2 \pm 1.1$ & $41.5 \pm 0.6$ & $7.92 \pm 0.21$ & $50.2 \pm 1.5$ & $1.49 \pm 0.16$ \\
\hline \multirow{2}{*}{ GOB } & MW & $10.7 \pm 1.3$ & $<2.0$ & $<6.0$ & $1.40 \pm 0.40$ & $6.33 \pm 0.73$ & $16.8 \pm 1.7$ & $2.30 \pm 0.20$ & $21.1 \pm 1.8$ & $0.35 \pm 0.02$ \\
\hline & DA & $12.2 \pm 1.6$ & $<2.0$ & $<6.0$ & $1.40 \pm 122$ & $7.29 \pm 0.85$ & $18.6 \pm 2.4$ & $2.35 \pm 0.40$ & $22.7 \pm 2.5$ & $0.31 \pm 0.04$ \\
\hline \multirow{2}{*}{ IND } & MW & $<10.0$ & $5.65 \pm 0.02$ & $<6.0$ & $4.11 \pm 1.10$ & $9.89 \pm 1.04$ & $10.1 \pm 0.5$ & $2.30 \pm 0.40$ & $113 \pm 13$ & $0.19 \pm 0.09$ \\
\hline & DA & $<10.0$ & $5.80 \pm 0.10$ & $<6.0$ & $3.57 \pm 0.51$ & $9.27 \pm 0.17$ & $11.1 \pm 0.7$ & $2.68 \pm 0.10$ & $121 \pm 2$ & $0.15 \pm 0.02$ \\
\hline \multirow{2}{*}{ SHN } & MW & $10.2 \pm 2.0$ & $5.15 \pm 0.10$ & $24.5 \pm 3.2$ & $3.60 \pm 0.35$ & $2.68 \pm 0.29$ & $33.2 \pm 4.0$ & $6.90 \pm 0.90$ & $22.5 \pm 2.6$ & $2.26 \pm 0.18$ \\
\hline & DA & $12.0 \pm 2.2$ & $4.42 \pm 1.20$ & $28.2 \pm 1.3$ & $3.25 \pm 0.78$ & $2.15 \pm 0.01$ & $37.2 \pm 1.0$ & $6.64 \pm 0.09$ & $24.6 \pm 0.7$ & $2.28 \pm 0.09$ \\
\hline
\end{tabular}


Despite the high content of organic matter due to the presence of carbohydrates in guarana-based beverages, the introduction of 2-fold diluted samples under the selected plasma-operating conditions did not cause analytical signal suppression or enhancement for the elements determined. This means that the eventual presence of carbon species or easily ionizable elements such as $\mathrm{Na}$ and $\mathrm{K}$ in the plasma did not cause severe non-spectral interferences in ICP OES measurements. Grindlay et al..$^{37}$ reported that carbon-containing solutions around $5.0 \mathrm{~g} \mathrm{~L}^{-1}$ caused more severe matrix effects for atomic lines in an analysis by ICP OES when high sample uptake rates were employed.

\section{Analytical performance}

Table S3 in the SI section shows the analytical parameters evaluated for direct analysis of guarana-based beverages by ICP OES, including limits of detection and quantification, precision (\% RSD), and working linear range. In general, the LOD and LOQ values obtained in this work were similar to other studies reported in the scientific literature, which used a minimum sample preparation for the multi-element determination in commercial carbonated beverage samples..$^{15,26,38}$ The low values demonstrate the good sensitivity of the proposed procedure and may be associated with small amounts of reagents employed for the sample preparation. In addition, the relative standard deviation was less than $10 \%$ for all measured analytes, suggesting an adequate precision for the proposed method..$^{32}$

\section{Accuracy}

The accuracy of the proposed analytical procedure was evaluated by analyzing the standard reference material trace elements in water (SRM NIST 1643f) and by addition-recovery experiments in a pool of the guaranabased beverages. The results are shown in Table S4 and S5 (see SI section). A statistical comparison between the certified and found values using the proposed procedure did not show a significant difference at the $95 \%$ confidence level for all elements except iron, which can be justified because the standard reference material is from a different matrix from the one analyzed. For the recovery tests, three different concentration levels were evaluated: 0.2 , 0.4 , and $0.6 \mathrm{mg} \mathrm{L}^{-1}$ for the analytes $\mathrm{Fe}, \mathrm{Cu}, \mathrm{Zn}$, and $\mathrm{Mn}$; 1.0, 2.0, and $3.0 \mathrm{mg} \mathrm{L}^{-1}$ for P; 2.0. 4.0 and $6.0 \mathrm{mg} \mathrm{L}^{-1}$ for $\mathrm{S}$; and 4.0, 8.0, and $12.0 \mathrm{mg} \mathrm{L}^{-1}$ for $\mathrm{Ca}, \mathrm{Mg}$, and $\mathrm{K}$. The recovery values ranged from 82 to $117 \%$ and were considered acceptable according to National Institute of Metrology, Quality and Technology (INMETRO), appropriate recovery between 80 to $120 \% .{ }^{32}$ Based on all these results, it is possible to conclude that the proposed procedure showed good accuracy.

Application of the procedure for direct analysis of guaranabased beverages

The proposed procedure was applied for the determination of $\mathrm{Cu}, \mathrm{Fe}, \mathrm{Mn}, \mathrm{Zn}, \mathrm{K}, \mathrm{Ca}, \mathrm{S}, \mathrm{P}$ and $\mathrm{Mg}$ in 28 guarana-based beverage samples (soft and energy drinks) from Itabuna and Ilhéus cities, Bahia, Brazil. The results are shown in Table 4. The found concentration ranges were (in $\mathrm{mg} \mathrm{L}^{-1}$ ) 0.36-43.3 (Ca), 4.04-192 (K), 0.36-44.8 (Mg), 10.1-1,073 (S), 0.04-92.4 (P), <0.010-0.0174 (Cu), <0.002-0.294 (Fe), $<0.006-0.06(\mathrm{Zn})$ and $<0.0006-0.168(\mathrm{Mn})$ for soft drink samples. These values were like those found by Silva et al. ${ }^{10}$ for energy drink samples, in which the ranges were 0.51-43.3 (Ca), 4.0-192 (K), 0.36-44.8 (Mg), 10.1-1,073 (S), 0.04-92.4 (P), < 0.010-0.02 (Cu), 0.002-0.03 (Fe), <0.006$0.09(\mathrm{Zn})$ and $<0.0006-0.17(\mathrm{Mn})$. Similar concentrations were also reported by Martins et al..$^{39}$ after analysis of several energy drink samples.

As can be observed in Table 4, high potassium concentrations (>33 $\left.\mathrm{mg} \mathrm{L}^{-1}\right)$ were found in guarana-based soft drinks. This may be associated with the high potassium contents in guarana seed extract ${ }^{40}$ and also by the addition of potassium sorbate as a food preservative in these beverages. ${ }^{15,41}$ In general, the concentration of essential macro and microelements in energy drinks were higher than in soft drinks, in which sulfur was the element in major abundance. Most energy drinks contain taurine $\left(\mathrm{C}_{2} \mathrm{H}_{7} \mathrm{NO}_{3} \mathrm{~S}\right)$, which acts on the central nervous system and contains sulfur in its chemical composition, contributing to the high concentrations of sulfur in these samples. For all guarana-based beverages analyzed in this work, we found that no sample had levels of essential elements above limits allowed by current legislation. ${ }^{42}$

\section{Conclusions}

The use of a Box-Behnken design combined with the desirability function for multi-response optimization was effective in the development of a simple analytical procedure based on direct analysis for the determination of $\mathrm{Ca}, \mathrm{K}$, $\mathrm{Mg}, \mathrm{P}, \mathrm{S}, \mathrm{Cu}, \mathrm{Fe}, \mathrm{Mn}$, and $\mathrm{Zn}$ in guarana-based beverage samples. The optimized procedure showed good precision, accuracy, and adequate limits for the quantification of all analytes. In addition, it meets one of the Green Chemistry concerns regarding the minimization of using concentrated reagents. The analytical procedure was successfully applied for the analysis of 28 guarana-based soft and energy drink samples from distinct brands, showing a difference between 
Table 4. Mean values of elements concentration in guarana-based beverage samples analyzed by ICP OES (mean \pm standard deviation) ${ }^{\mathrm{a}}$

\begin{tabular}{|c|c|c|c|c|c|c|c|c|c|c|}
\hline Beverage & Sample code & $\begin{array}{c}\mathrm{Cu} / \\
\left(\mu \mathrm{g} \mathrm{L}^{-1}\right)\end{array}$ & $\begin{array}{c}\mathrm{Fe} / \\
\left(\mu \mathrm{g} \mathrm{L}^{-1}\right)\end{array}$ & $\begin{array}{c}\mathrm{Zn} \mathrm{/} \\
\left(\mu \mathrm{g} \mathrm{L}^{-1}\right)\end{array}$ & $\begin{array}{c}\mathrm{Mn} / \\
\left(\mu \mathrm{g} \mathrm{L}^{-1}\right)\end{array}$ & $\begin{array}{c}\mathrm{Ca} / \\
\left(\mathrm{mg} \mathrm{L}^{-1}\right)\end{array}$ & $\begin{array}{c}\mathrm{K} / \\
\left(\mathrm{mg} \mathrm{L}^{-1}\right)\end{array}$ & $\begin{array}{c}\mathrm{Mg} / \\
\left(\mathrm{mg} \mathrm{L}^{-1}\right)\end{array}$ & $\begin{array}{c}\mathrm{S} / \\
\left(\mathrm{mg} \mathrm{L}^{-1}\right)\end{array}$ & $\begin{array}{c}\mathrm{P} / \\
\left(\mathrm{mg} \mathrm{L}^{-1}\right)\end{array}$ \\
\hline \multirow{14}{*}{ Soft drink } & KTP & $<10.0$ & $33.7 \pm 5.2$ & $<6.0$ & $2.45 \pm 0.51$ & $16.2 \pm 1.1$ & $41.5 \pm 0.6$ & $7.92 \pm 0.21$ & $50.2 \pm 1.5$ & $1.49 \pm 0.16$ \\
\hline & $\mathrm{KT}^{\mathrm{b}}$ & $<10.0$ & $21.6 \pm 1.8$ & $19.1 \pm 1.3$ & $12.2 \pm 1.2$ & $16.2 \pm 0.9$ & $51.5 \pm 3.1$ & $8.15 \pm 0.61$ & $52.3 \pm 4.4$ & $1.55 \pm 0.04$ \\
\hline & FTP & $10.2 \pm 1.5$ & $2.58 \pm 0.81$ & $<6.00$ & $6.56 \pm 0.46$ & $18.3 \pm 0.2$ & $59.8 \pm 4.5$ & $8.20 \pm 0.25$ & $16.4 \pm 0.1$ & $1.46 \pm 0.14$ \\
\hline & $\mathrm{FT}^{\mathrm{b}}$ & $10.8 \pm 1.1$ & $2.70 \pm 0.57$ & $40.2 \pm 2.1$ & $24.3 \pm 1.2$ & $20.8 \pm 2.2$ & $51.4 \pm 3.1$ & $8.44 \pm 0.37$ & $16.6 \pm 0.7$ & $4.31 \pm 0.28$ \\
\hline & GA & $<10.0$ & $61.5 \pm 2.6$ & $<6.0$ & $3.32 \pm 0.53$ & $2.08 \pm 0.12$ & $16.7 \pm 0.4$ & $1.99 \pm 0.08$ & $10.5 \pm 0.4$ & $0.54 \pm 0.04$ \\
\hline & $\mathrm{GA}^{\mathrm{b}}$ & $<10.0$ & $5.40 \pm 1.2$ & $<6.0$ & $5.98 \pm 0.54$ & $6.37 \pm 0.72$ & $15.7 \pm 0.2$ & $1.82 \pm 0.07$ & $15.2 \pm 1.3$ & $0.41 \pm 0.12$ \\
\hline & $\mathrm{GAZ}^{\mathrm{b}}$ & $13.4 \pm 0.5$ & $20.1 \pm 0.1$ & $30.5 \pm 2.6$ & $5.77 \pm 0.72$ & $4.27 \pm 0.12$ & $20.3 \pm 0.06$ & $1.69 \pm 0.31$ & $29.0 \pm 4.0$ & $0.04 \pm 0.01$ \\
\hline & IND & $<10.0$ & $5.80 \pm 0.10$ & $<6.0$ & $3.57 \pm 0.51$ & $9.27 \pm 0.17$ & $11.1 \pm 0.7$ & $2.68 \pm 0.10$ & $121 \pm 2$ & $0.15 \pm 0.02$ \\
\hline & SHN & $12.0 \pm 2.2$ & $4.42 \pm 1.20$ & $28.2 \pm 1.3$ & $3.25 \pm 0.78$ & $2.15 \pm 0.01$ & $37.2 \pm 1.0$ & $6.64 \pm 0.09$ & $24.6 \pm 0.7$ & $2.28 \pm 0.09$ \\
\hline & TUB & $11.3 \pm 0.4$ & $85.2 \pm 3.7$ & $<6.0$ & $45.4 \pm 2.0$ & $62.4 \pm 2.2$ & $7.38 \pm 0.15$ & $44.8 \pm 2.0$ & $65.0 \pm 2.2$ & $92.4 \pm 4.1$ \\
\hline & GOB & $12.2 \pm 1.6$ & $<2.0$ & $<6.0$ & $1.40 \pm 0.22$ & $7.29 \pm 0.85$ & $18.6 \pm 2.4$ & $2.35 \pm 0.40$ & $22.7 \pm 2.5$ & $0.31 \pm 0.04$ \\
\hline & GRO & $13.5 \pm 1.0$ & $66.2 \pm 8.9$ & $<6.0$ & $29.0 \pm 1.8$ & $23.9 \pm 0.6$ & $20.9 \pm 0.9$ & $3.82 \pm 0.15$ & $23.8 \pm 0.8$ & $0.93 \pm 0.03$ \\
\hline & IT & $11.5 \pm 2.0$ & $15.2 \pm 2.9$ & $<6.0$ & $2.61 \pm 0.54$ & $0.36 \pm 0.09$ & $27.8 \pm 1.4$ & $2.63 \pm 0.65$ & $10.1 \pm 1.0$ & $0.24 \pm 0.01$ \\
\hline & SMB & $10.5 \pm 0.8$ & $<2.0$ & $21.6 \pm 0.5$ & $2.21 \pm 0.46$ & $8.70 \pm 0.78$ & $45.7 \pm 1.0$ & $3.11 \pm 0.12$ & $36.4 \pm 1.9$ & $1.69 \pm 0.08$ \\
\hline \multirow{14}{*}{ Energy drink } & MGT & $10.9 \pm 1.7$ & $127 \pm 8$ & $<6.0$ & $8.77 \pm 0.46$ & $18.7 \pm 0.4$ & $32.5 \pm 0.7$ & $3.27 \pm 0.11$ & $553 \pm 4$ & $0.45 \pm 0.12$ \\
\hline & $\mathrm{FUS}^{\mathrm{b}}$ & $15.3 \pm 0.8$ & $20.3 \pm 0.5$ & $18.1 \pm 4.0$ & $11.4 \pm 0.4$ & $5.57 \pm 0.50$ & $158 \pm 1$ & $1.00 \pm 0.05$ & $1073 \pm 43$ & $0.63 \pm 0.09$ \\
\hline & $\mathrm{MNT}^{\mathrm{b}}$ & $16.5 \pm 1.2$ & $54.5 \pm 4.3$ & $27.3 \pm 3.1$ & $6.77 \pm 0.53$ & $0.51 \pm 0.13$ & $4.04 \pm 0.20$ & $0.36 \pm 0.01$ & $1056 \pm 64$ & $1.88 \pm 0.09$ \\
\hline & BIV & $11.7 \pm 2.5$ & $47.0 \pm 2.1$ & $<6.0$ & $12.2 \pm 0.7$ & $15.8 \pm 1.4$ & $110 \pm 1$ & $23.5 \pm 0.4$ & $1007 \pm 22$ & $0.73 \pm 0.04$ \\
\hline & EUP & $10.7 \pm 0.5$ & $10.8 \pm 1.0$ & $<6.0$ & $10.0 \pm 0.8$ & $1.56 \pm 0.18$ & $17.7 \pm 0.9$ & $2.14 \pm 0.12$ & $1006 \pm 8$ & $0.16 \pm 0.01$ \\
\hline & FTB & $11.1 \pm 1.3$ & $49.1 \pm 2.4$ & $21.0 \pm 0.4$ & $41.5 \pm 0.3$ & $19.7 \pm 1.1$ & $28.5 \pm 0.7$ & $2.59 \pm 0.09$ & $65.5 \pm 1.9$ & $0.73 \pm 0.05$ \\
\hline & GRT & $<10.0$ & $124 \pm 6$ & $10.4 \pm 1.3$ & $66.3 \pm 1.7$ & $36.4 \pm 1.06$ & $43.9 \pm 2.4$ & $23.7 \pm 0.5$ & $166 \pm 3$ & $0.55 \pm 0.02$ \\
\hline & GRM & $11.2 \pm 1.8$ & $113 \pm 5$ & $9.72 \pm 0.58$ & $20.7 \pm 0.4$ & $13.9 \pm 1.0$ & $192 \pm 5$ & $1.95 \pm 0.10$ & $137 \pm 4$ & $0.88 \pm 0.05$ \\
\hline & GNT & $17.4 \pm 2.0$ & $266 \pm 30$ & $27.2 \pm 1.8$ & $30.8 \pm 2.7$ & $13.5 \pm 1.0$ & $6.6 \pm 0.4$ & $3.83 \pm 0.23$ & $157 \pm 17$ & $0.47 \pm 0.01$ \\
\hline & GFT & $<10.0$ & $31.1 \pm 2.0$ & $<6.0$ & $104 \pm 3$ & $10.7 \pm 0.6$ & $58.5 \pm 4.5$ & $10.0 \pm 0.1$ & $191 \pm 1$ & $0.47 \pm 0.04$ \\
\hline & GRX & $<10.0$ & $158 \pm 2$ & $60 \pm 3.5$ & $26.1 \pm 1.5$ & $5.85 \pm 0.58$ & $69.6 \pm 2.0$ & $4.42 \pm 0.10$ & $141 \pm 7$ & $0.40 \pm 0.01$ \\
\hline & FTZ & $14.4 \pm 1.0$ & $235 \pm 5$ & $9.45 \pm 0.25$ & $34.0 \pm 0.9$ & $1.39 \pm 0.35$ & $87.8 \pm 5.6$ & $2.32 \pm 0.13$ & $80.0 \pm 0.2$ & $0.25 \pm 0.01$ \\
\hline & GRH & $11.2 \pm 0.6$ & $290 \pm 4$ & $<6.0$ & $168 \pm 4$ & $43.3 \pm 1.3$ & $42.3 \pm 1.1$ & $30.7 \pm 0.6$ & $168 \pm 4$ & $0.39 \pm 0.14$ \\
\hline & $\mathrm{ICE}$ & $12.1 \pm 1.3$ & $294 \pm 12$ & $26.2 \pm 1.7$ & $20.5 \pm 0.01$ & $4.50 \pm 0.62$ & $38.6 \pm 0.4$ & $2.38 \pm 0.01$ & $70.0 \pm 2.0$ & $0.73 \pm 0.06$ \\
\hline \multirow{2}{*}{ Average } & soft drink & 10.0 & 22.0 & 17.0 & 11.0 & 14.9 & 33.3 & 7.87 & 37.2 & 1.23 \\
\hline & energy drink & 11.0 & 113.0 & 29.0 & 36.0 & 13.2 & 58.8 & 7.30 & 402.2 & 0.60 \\
\hline
\end{tabular}

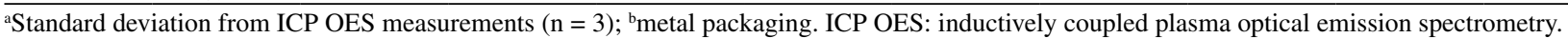

the concentration of the analytes in investigated beverage samples, especially for the macro elements $\mathrm{K}, \mathrm{Mg}, \mathrm{S}$, and P. However, no difference was noted between the beverage samples from plastic or metallic packaging.

\section{Supplementary Information}

Supplementary information (intensity results obtained for each analyte from ICP OES measurements, and analytical performance data) is available free of charge at http://jbcs.sbq.org.br as PDF file.

\section{Acknowledgments}

The authors acknowledge the financial support of the Fundação de Amparo à Pesquisa do Estado da Bahia (FAPESB) and the Conselho Nacional de Desenvolvimento Científico e Tecnológico (CNPq) T.O PNE 011/2014, and the Comissão Executiva do Plano da Lavoura Cacaueira (CEPLAC).

\section{Author Contributions}

Vinnícius Henrique C. da Silva is the main author of the work, which was developed during his master's, being responsible for formal analysis, investigation, methodology, writing an original draft, writing, review and editing and verification tests. André Luiz S. da Silva Jr. was responsible for the formal analysis, writing, review and editing; Herick M. Santos for the writing, review and editing; Ivon P. Lôbo for the visualization, writing original draft, writing, review and editing; Marcos de A. Bezerra for the visualization, writing original draft, writing-review and editing; Raildo M. de Jesus for the conceptualization, supervision, funding acquisition, project administration and resources.

\section{References}

1. Mendes, T. M. N.; Murayama, Y.; Yamaguchi, N.; Sampaio, G. R.; Fontes, L. C. B.; Torres, E. A. F. S.; Tamura, H.; Yonekura, L.; J. Funct. Foods 2019, 55, 352. 
2. Brazilian Institute of Geography and Statistics (IBGE); Levantamento Sistemático da Produção Agrícola, available at http://www.sidra.ibge.gov.br/bda/prevsaf/, accessed in September 2018.

3. Miguel, C.; Kuri, B.; Int. Bus. Econ. Res. J. 2008, 7, 87.

4. Machado, K. N.; de Freitas, A. A.; Cunha, L. H.; Faraco, A. A. G.; de Pádua, R. M.; Braga, F. C.; Vianna-Soares, C. D.; Castilho, R. O.; Food Chem. 2018, 239, 180.

5. McKay, C.; Scharman, E. J.; Emerg. Med. Clin. North Am. 2015 , 33, 153.

6. Styburski, D.; Dec, K.; Baranowska-Bosiacka, I.; Goschorska, M.; Hołowko, J.; Żwierełło, W.; Skórka-Majewicz, M.; Janda, K.; Rosengardt, A.; Gutowska, I.; Biol. Trace Elem. Res. 2020, 197, 341.

7. Leśniewicz,A.; Grzesiak, M.;Żyrnicki,W.; Borkowska-Burnecka, J.; Biol. Trace Elem. Res. 2016, 170, 485.

8. Zoroddu, M. A.; Aaseth, J.; Crisponi, G.; Medici, S.; Peana, M.; Nurchi, V. M.; J. Inorg. Biochem. 2019, 195, 120.

9. Word Health Organization (WHO); Guideline: Sodium Intake for Adults and Children, 2012, available at https://www.who.int/ publications/i/item/9789241504836, accessed in March 2021.

10. Silva, E. S.; da Silva, E. G. P.; Silva, D. S.; Novaes, C. G.; Amorim, F. A. C.; dos Santos, M. J. S.; Bezerra, M. A.; Food Chem. 2019, 273, 9.

11. Ferreira, E. C.; Rodrigues, S. H. B. G.; Ferreira, M. M. C.; Nóbrega, J. A.; Nogueira, A. R. A.; Ecletica Quim. 2002, 27, 77.

12. Lerner, N.; Sedgi, I.; Chernia, Z.; Zeiri, O.; Talanta 2019, 199, 662.

13. Zucchi, O. L. A. D.; Moreira, S.; Salvador, M. J.; Santos, L. L.; J. Agric. Food Chem. 2005, 53, 7863.

14. Ghuniem, M. M.; Khorshed, M. A.; Souaya, E. R.; Int. J. Environ. Anal. Chem. 2019, 99, 515.

15. Kilic, S.; Cengiz, M. F.; Kilic, M.; Environ. Monit. Assess. 2018 , 190, 202.

16. Fernández-López, L.; Gómez-Nieto, B.; Gismera, M. J.; Sevilla, M. T.; Procopio, J. R.; Spectrochim. Acta, Part B 2018, 147, 21.

17. Ackah, M.; Anim, A. K.; Zakaria, N.; Osei, J.; Saah-Nyarko, E.; Gyamfi, E. T.; Tulasi, D.; Enti-Brown, S.; Hanson, J.; Bentil, N. O.; Environ. Monit. Assess. 2014, 186, 8499.

18. Szymczycha-Madeja, A.; Welna, M.; Jedryczko, D.; Pohl, P.; TrAC, Trends Anal. Chem. 2014, 55, 68.

19. Marques, T. L.; Wiltsche, H.; Nóbrega, J. A.; Winkler, M.; Knapp, G.; Anal. Bioanal. Chem. 2017, 409, 4449.

20. Flores, E. M. M.; Microwave-Assisted Sample Preparation for Trace Element Determination; Elsevier: Oxford, UK, 2014.

21. Korn, M. G. A.; Morte, E. S. B.; dos Santos, D. C. M. B.; Castro, J. T.; Barbosa, J. T. P.; Teixeira, A. P.; Fernandes, A. P.; Welz, B.; dos Santos, W. P. C.; dos Santos, E. B. G. N.; Korn, M.; Appl. Spectrosc. Rev. 2008, 43, 67.

22. Pohl, P.; Dzimitrowicz, A.; Jamroz, P.; Greda, K.; Talanta 2018 , 189, 182.
23. Ferreira, S. L. C.; Silva Jr., M. M.; Felix, C. S. A.; da Silva, D. L. F.; Santos, A. S.; Santos Neto, J. H.; de Souza, C. T.; Cruz Jr., R. A.; Souza, A. S.; Food Chem. 2019, 273, 3.

24. Jalbani, N.; Kazi, T. G.; Arain, B. M.; Jamali, M. K.; Afridi, H. I.; Sarfraz, R. A.; Talanta 2006, 70, 307.

25. Castro, M. T. P. O.; Baccan, N.; Talanta 2005, 65, 1264.

26. Froes, R. E. S.; Borges Neto, W.; Naveira, R. L. P.; Silva, N. C.; Nascentes, C. C.; da Silva, J. B. B.; Microchem. J. 2009, 92, 68.

27. Milani, R. F.; Morgano, M. A.; Cadore, S.; Food Anal. Methods 2018, 11, 1763.

28. Novaes, C. G.; Bezerra, M. A.; da Silva, E. G. P.; dos Santos, A. M. P.; Romão, I. L. S.; Santos Neto, J. H.; Microchem. J. 2016, 128, 331.

29. Derringer, G.; Suich, R.; J. Qual. Technol. 2018, 12, 214.

30. Statistica, version 12.0; StatSoft Inc., Tulsa, OK, USA, 2013.

31. Desing-Expert, version 6.0.4; Stat-Ease, Inc., Minneapolis, MN, 2001.

32. National Institute of Metrology, Quality and Technology (INMETRO); Orientação sobre Validação de Métodos Analíticos - August 2016, available at http://www.inmetro.gov. br/Sidoq/Arquivos/CGCRE/DOQ/DOQ-CGCRE-8_05.pdf, accessed in March 2021.

33. Silva, F. V.; Trevizan, L. C.; Silva, C. S.; Nogueira, A. R. A.; Nóbrega, J. A.; Spectrochim. Acta, Part B 2002, 57, 1905.

34. Dennaud, J.; Howes, A.; Poussel, E.; Mermet, J. M.; Spectrochim. Acta, Part B 2001, 56, 101.

35. Todoli, J. L.; Mermet, J. M.; Encyclopedia of Analytical Chemistry; John Wiley \& Sons, Ltd.: New Jersey, USA, 2011.

36. Szymczycha-Madeja, A.; Welna, M.; Pohl, P.; J. Braz. Chem. Soc. 2013, 24, 1606.

37. Grindlay, G.; Gras, L.; Mora, J.; de Loos-Vollebregt, M. T. C.; Spectrochim. Acta, Part B 2008, 63, 234.

38. Tormen, L.; Torres, D. P.; Dittert, I. M.; Araújo, R. G. O.; Frescura, V. L. A.; Curtius, A. J.; J. Food Compos. Anal. 2011, 24, 95.

39. Martins, A. S.; Junior, J. B. P.; de Araújo Gomes, A.; Carvalho, F. I. M.; Filho, H. A. D.; Dantas, K. G. F.; Biol. Trace Elem. Res. 2019, 194, 284.

40. Santos, H. M.; Coutinho, J. P.; Amorim, F. A. C.; Lôbo, I. P.; Moreira, L. S.; Nascimento, M. M.; de Jesus, R. M.; Food Chem. 2019, 273, 159.

41. Ferrari, C. C.; Soares, L. M. V.; Ciênc. Tecnol. Aliment. 2003, $23,414$.

42. Ministério da Saúde (Brasil); Decreto No. 55.871 de 26 de março de 1965, Dispõe sobre Normas Reguladoras do Emprego de Aditivos para Alimentos - Revogado, available at http:// www.planalto.gov.br/ccivil_03/decreto/1950-1969/d55871. htm, accessed in March 2021.

Submitted: September 22, 2020

Published online: April 6, 2021 